\title{
Earthquake Swarm Recorded by an Ocean Bottom Seismic Array in Southwest Offshore of Taiwan in October, 2005
}

\author{
Emmy T. Y. Chang ${ }^{1,}$, Shu-Kun Hsu ${ }^{2}$, and Chao-Shing Lee ${ }^{3}$ \\ ${ }^{1}$ Institute of Oceanography, National Taiwan University, Taipei, Taiwan, ROC \\ ${ }^{2}$ Department of Earth Sciences, National Central University, Chung-Li, Taiwan, ROC \\ ${ }^{3}$ Institute of Applied Earth Science, National Taiwan Ocean University, Keelung, Taiwan, ROC
}

Received 4 February 2008, accepted 26 September 2008

\begin{abstract}
We conduct a detailed analysis of the seismic records for 406 marine earthquakes in SW offshore of Taiwan recorded by a small OBS array during $7-12$ October 2005. The spatial distribution of the events, which included a complete main shock-aftershock sequence, show concentration in a vertical chain reaching $40 \mathrm{~km}$ in depth and that the deeper events slightly turns to the NE toward the Taiwan island. We use these recorded data to construct a 1-D layered velocity model for the local lithosphere. The model puts the Moho at around $13 \mathrm{~km}$ in depth and plate seismogenic thickness at about $40 \mathrm{~km}$ for the studied area. Our observations reveal that the local seismogenic structure is consistent with the character of the oceanic-origin crust and a non-subducting related mechanism. We also examine the polarizations of $P$-, $S$ - wave first arrivals and $P$-to- $S V$ ratios in the waveform to obtain focal mechanism solutions for a total of 26 events. However, their solutions particularly show a non-unique deforming comportment for the strain releases, implying a strain rebound corresponding to the back-and-forth motion and also affected by the complexity of the pre-existing structure in the region.
\end{abstract}

Key words: Manila trench, OBS, Subduction, Continental-oceanic transition, Earthquake location, Focal mechanism solution

Citation: Chang, E. T. Y., S. K. Hsu, and C. S. Lee, 2008: Earthquake swarm recorded by an ocean bottom seismic array in southwest offshore of Taiwan in October, 2005. Terr. Atmos. Ocean. Sci., 19, 717-728, doi: 10.3319/TAO.2008.19.6.717(PT)

\section{INTRODUCTION}

The island of Taiwan is remarkable in the sense that it is created by two subduction systems: the Ryukyu system to the northeast and the Manila system to the southwest (Fig. 1), both as portions of the plate boundaries joining the Philippine Sea plate and the Asian plate at the western border of the Circum-Pacific seismic belt. The Philippine Sea plate is moving toward the southeast Asian plate at relative velocity of $82 \mathrm{~mm} \mathrm{yr}^{-1}$ in the direction of $310^{\circ}$ (Yu et al. 1997). The deformation front is the western boundary of the thrust-and-fold belt and generally considered to connect the Manila trench in space. In comparison with the active Ryukyu subduction system, the subduction mechanism along the Manila trench approaching Taiwan is relatively inactive as its corresponding Wadati-Benioff zone is of less obvious feature than the Ryukyu subducting plate. The recent earthquake reports officially issued by Taiwan's Central Weather

\footnotetext{
* Corresponding author

E-mail:etychang@ntu.edu.tw
}

Bureau (CWB) also show a sparse seismicity with few large earthquakes towards the northernmost end of the Manila trench - or the area SW offshore of Taiwan. However, the seismic observations in the southern Taiwan reveal a complex image for the Manila subduction system - a high velocity zone and concentrated seismicity at a depth of 15 $50 \mathrm{~km}$ beneath the Coastal Range and the Philippine Sea around the latitudes of $22^{\circ} \sim 23^{\circ}$ (Tsai 1986; Rau and Wu 1995; Wang and Shin 1998). This feature is the eastern part of the Manila subducting plate, resulting in an obscure seismotectonic regime of the Manila subduction system in southern Taiwan around the latitudes $21^{\circ} \sim 22^{\circ}$.

Another debate for the south offshore Taiwan concerns the oceanic-continental transition from the South China Sea (SCS) to the Southeast Asian continent. Formation of the SCS appears to be the cause of the opening introduced by the India-Asia collision (Tapponnier et al. 1982), or alternatively that of the passive marginal subduction (e.g., Taylor and Hayes 1980; Rangin et al. 1999), or some other schemes. 


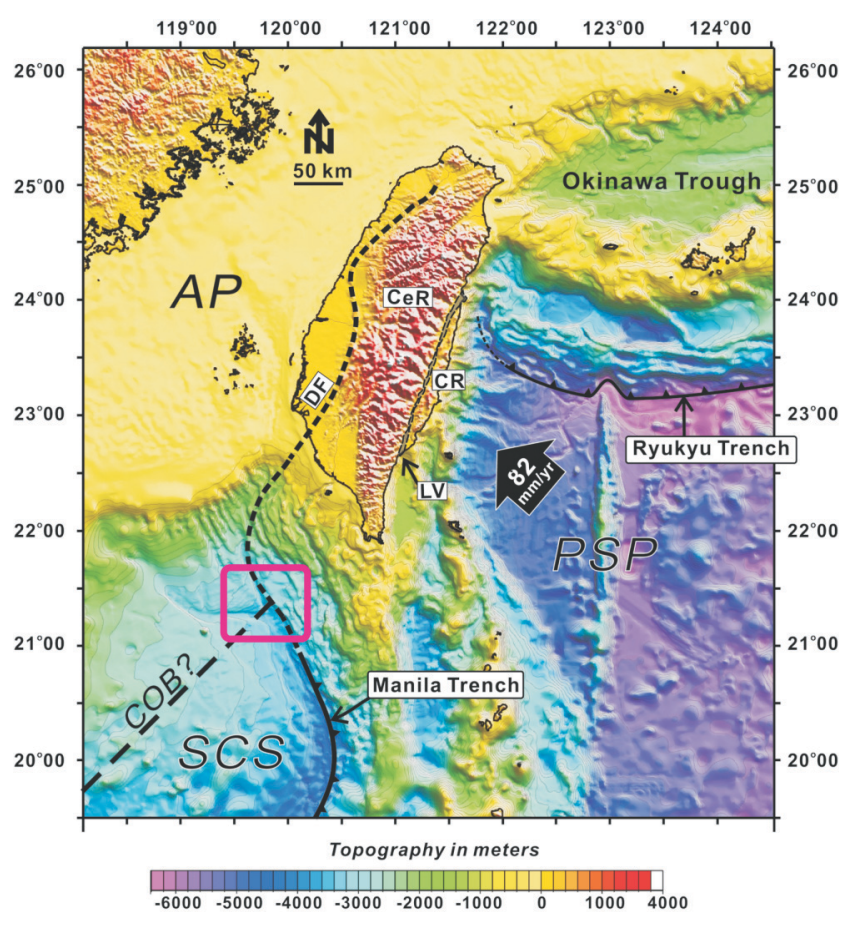

Fig. 1. Regional bathymetric map and the principal tectonic units around Taiwan. The pink rectangle marks our OBS array. PSP: Philippine Sea Plate; AP: Asian Plate; CeR: Central Range (Taiwan); CR: Coastal Range; LV: longitudinal valley; DF: deformation front.

With the identification of magnetic lineation in the SCS basin, the extension of the SCS basin occurred during 32 to $15 \mathrm{Ma}$ before present (magnetic anomaly C11 - C5c) (Taylor and Hayes 1980; Briais et al. 1993), and the continent-ocean boundary (COB) reached the latitude of $19^{\circ} \mathrm{N}$ in SW off Taiwan. Recent studies with new magnetic and gravity surveys indicate that the COB for the SCS and the SE Asia could extend further to the north, reaching $20^{\circ} \mathrm{N}$ (Hsu and Sibuet 2004; Hsu et al. 2004; Wu et al. 2004) and the oldest age of SCS opening is about $37.8 \mathrm{Ma}$ (Hsu et al. 2004). Sibuet et al. (2004) further proposed that the continent-ocean transition of the northern SCS could extend toward northeast to lie under south Taiwan and the Philippine Sea plate. It appears that the local properties of the deep lithospherical mechanics at the SW off Taiwan play a key role in the issue of COB distribution, and furthermore, in constructing the plate deformation at the northernmost Manila subduction system.

For marine earthquakes, land seismic observations often suffer from lacking in azimuthal coverage and being far from the epicenter. Small-to-moderate foci are thus often missed. Recently, these problems have been remedied using ocean bottom seismometers (OBS). OBS is designed as a self contained data acquisition system which free falls to the ocean bottom and records ground motion generated by seismic sources. It lends aids to a variety of scientific investigations ranging from deep earth structure to surface geological processes.
In this study, we use data from a short-period array of seven Ocean-Bottom Seismometers (OBS) deployed in the SW offshore Taiwan during 7 - 12 October 2005. The deploying area is set at the joint point of the SCS plate, the $\mathrm{COB}$, and the Asian plate. In the five recording days, our small OBS array captured more than 400 distinct earthquakes within its range. Based on an inferred 1-D layered velocity model of the local lithosphere, we study the characteristics of the earthquakes in terms of the spatial and temporal distribution and their seismogenic setting (Figs. 1, 2), which shows that the seismogenesis in the SW offshore Taiwan is more complex than thought before.

\section{DATA}

Named "MicrOBS", the OBSs are short-period devices newly developed by the Institut Français de recherche pour l'exploitation de la mer (ifremer) (Auffret et al. 2004). Logistically simple and inexpensive, the system is powered by a rechargeable LI ION pack battery which can function at sea bottom up to $5000 \mathrm{~m}$ of water in depth for up to two weeks (Auffret et al. 2004). Typically, MicrOBS is designed for use in seismic refraction experiments; in this study we use it for detection of tectonic earthquakes.

There are four sensors with each MicrOBS: one hydrophone, one vertical geophone, and two horizontal geophones. The main electronic card consists of a 24-bit analog-to-digital convertor. The internal temperature-compensated crystal oscillator (TXCO) clock is accurate to 2 parts in $10^{7}$ and tends to drift quite linearly at the nearly constant temperature on the seafloor. Time calibrations conducted before and after deployment with a Global Positioning System clock allow corrections to be made that result in accuracy of 1 part in $10^{8}$. Data are continuously stored in flashcard memory (in $2 \mathrm{~Gb}$ ).

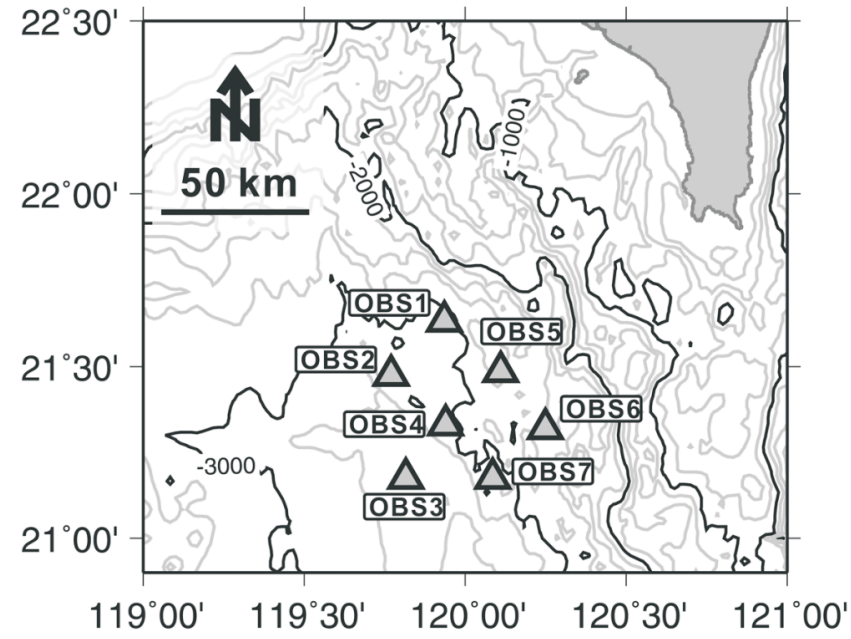

Fig. 2. Location of the 7 MicrOBS stations. The inter-station distance is around $25 \mathrm{~km}$. 
Certain factors about the OBS are considered in comparison with the seismograms acquired from onland seismic sensors:

(i) The background noise on the sea bottom tends to be higher, while the shape of the noise spectrum is skewed to the low frequencies below $0.1 \mathrm{~Hz}$ (Webb 1998; Pulliam et al. 2003). For the same reason, there presumably should be a higher seismicity rate than actually detected by OBS instruments.

(ii) Identifying seismic phases is somewhat more difficult for OBSs. This is because of the relatively weak coupling of the instrument with the poorly consolidated, water-saturated sediment environment.

(iii) The same factor above means a relatively higher damping of the seismic signals, strongly attenuating the amplitudes of higher frequencies. (iv) As there is no device for determining the actual horizontal orientation of the OBS, directional adjustment has to be processed with the senses of signals. This calibration does not influence the $P$-, $S$ - first-arrival picks for earthquake location but make possible the identification of polarized seismic phases in the subsequent analyses. The principle is to compare the real back-azimuth of station (BA) with the apparent back-azimuth (BA') seen from raw seismograms; the latter is evaluated by the nature of $P$-wave polarization through using the three-component vector ground motion and the fact that the $P$-wave motion is polarized in the vertical and radial plane. Figure 3 is an example of the polarization of the direct $P$-phase observed at Station OBS03. It is apparent that the $P$ wave travels along the $\mathrm{H} 2$ direction, so that there is little motion in the $\mathrm{H} 1$ direction (Figs. 3a, c). Figure 3b illus-

(a)

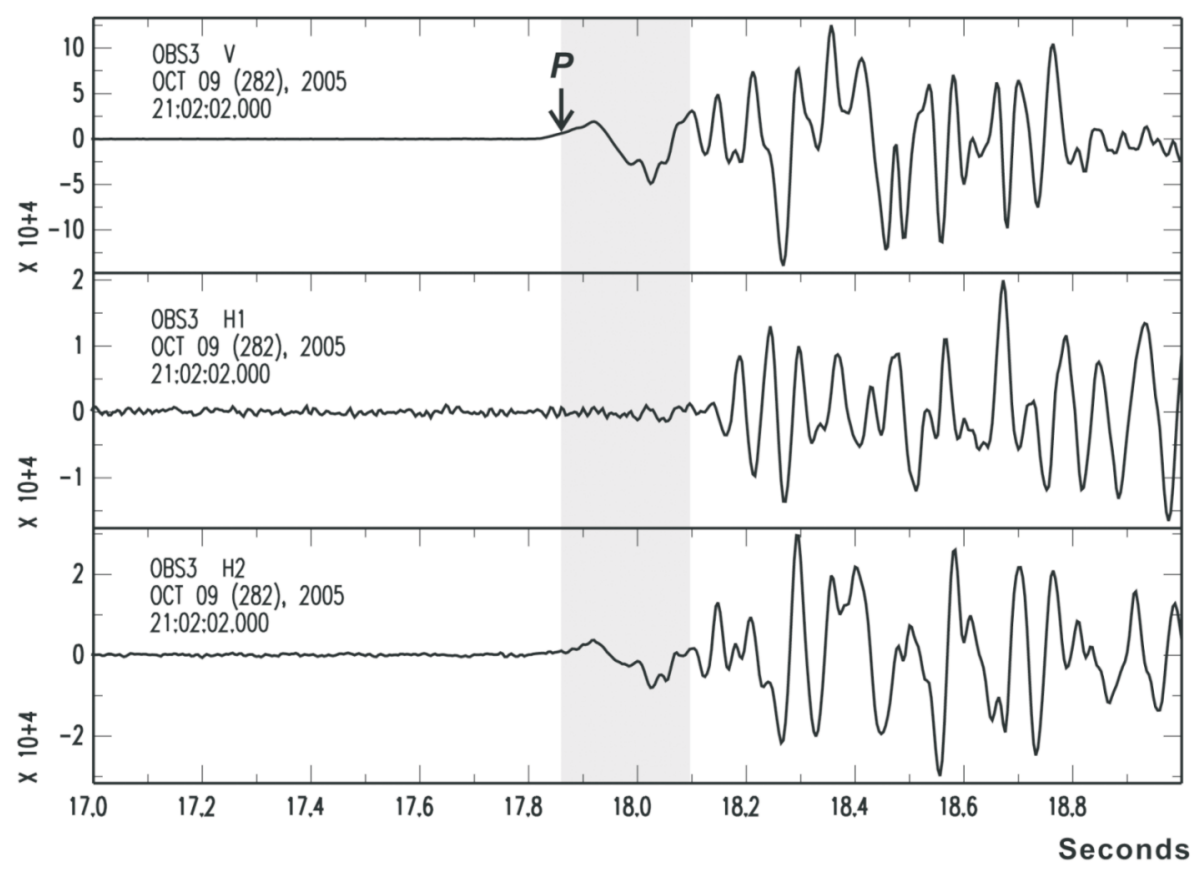

(b)

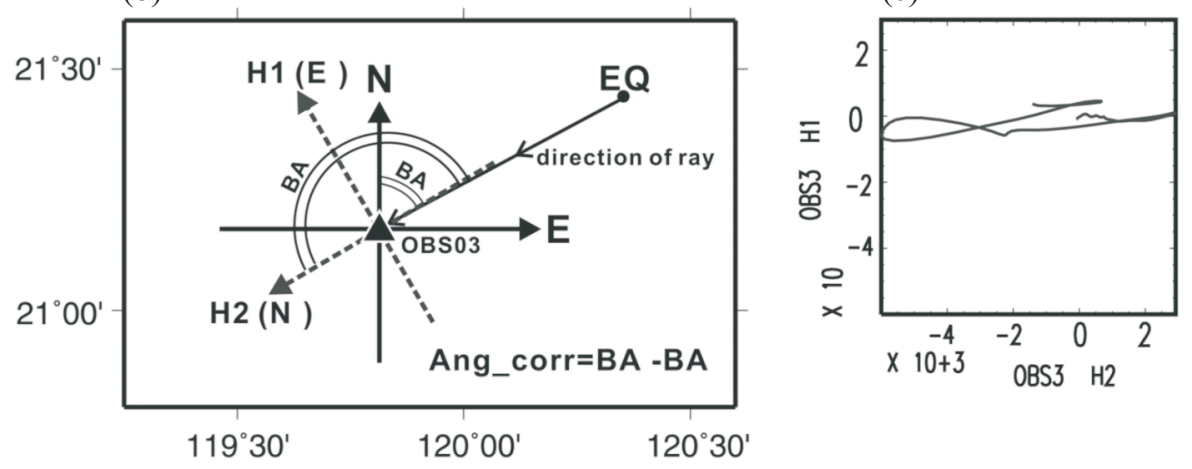

Fig. 3. Procedure for determining the angular correction for the OBS horizontal orientation (components H1 and H2) relative to the geographic EW-NS coordinates. (a) The shadow indicates the direct $P$-phase in three components, whose polarizations conform to BA'. (b) The geometric relationship between BA and BA'. (c) The particle motion composed of the H1 and H2 component motions. 
trates the spatial geometry of the earthquake and Station OBS03. The correcting angle for the two MicrOBS horizontal components to the geographical NS-EW directions can therefore be determined by the discrepancy between BA and BA' in this case. Table 1 lists the angles which were used to correct the component H1 (in the positive sense) to the geographic East, and H2 (in the positive sense) to the geographic North. Uncertainty of this estimation is generally less than 13 degrees.

The majority of the 406 earthquakes detected by our OBS array are of small-to-moderate magnitude, generally smaller than 3.0. The mainshock of the earthquake sequence mentioned above turns out to be magnitude 4.5 , occurring on October 9. The magnitude is determined as follows. We adopt the definition of the local magnitude $\left(\mathrm{M}_{\mathrm{L}}\right)$ to avoid the effect of high noise embedded within the OBS seismograms. Peak ground motion amplitude $A$ defined as the geometrical mean of the two horizontal peak amplitudes (in units of count) in consideration of the attenuation with increasing epicentral distance, $D$ (Gutenberg and Richter 1956). The empirical relationship between $\mathrm{M}_{\mathrm{L}}$ and $D$ (in $\mathrm{km}$ ) is:

$\ln (A)=(21.0 \pm 0.5)-(3.2 \pm 0.3) \ln (D)+(0.8 \pm 0.1) \mathrm{M}_{\mathrm{L}}$

Examples of event location are presented in Fig. 4, by aligning the waveforms with their epicentral distances. Proper location leads to the timing of phase onset as a function of distance (Fig. 4). The waveforms in Fig. 4 are non-scaled. The seismograms sometimes exhibiting a high noise or an abnormal damping were excluded from processing location (for instance, Stations OBS01 and OBS02 in Fig. 4c). The repeated occurrences of earthquakes in a very short term (in 20 seconds) were detected within our OBS. In the windows of Figs. $4 \mathrm{c}$ and d, there are respectively 2 and 3 earthquakes which can be identified by their seismic onsets, and the re- corded waveforms are similar for the near events along the time axis for each individual station, whose phases' travel times are consistent for all stations. We infer that there are sustained releases of seismic energy, which occur along the existing structural planes. As such a phenomenon of repeated occurrence of earthquake is frequently observed in our OBS seismograms, and sometimes the time intervals of the repeated occurrence can be less than 10 seconds (see Fig. 4d).

\section{SEISMIC PARAMETER ANALYSIS AND RESULTS}

Prior to our installation of the OBS array, there were only some seismic profiles implemented by active sources to recover compressional wave velocity in the shallow layers at SW offshore Taiwan (e.g., Chen and Jaw 1996; Liu et al. 1997; Nakamura et al. 1998; McIntosh et al. 2005). It is inadequate to construct seismic velocity reference for earthquake locationing. In this study, with a considerable number of local earthquake records, we can construct a 1-D layered velocity model for the area.

With only the arrival times of seismic onsets, it is a trade-off to derive the velocity structure and the earthquake hypocenter. The general approach is to iterate the process of accommodating velocity structure and re-determining earthquake location (Kissling et al. 1994). However, this iterative inversion approach does not guarantee convergence. Here we adopt the method of Pavlis and Booker (1980) which is able to simultaneously determine the velocity structure and earthquake hypocenters. We set the inversion of 1-D velocity model as a linear problem consisting of a continuous function and a set of discrete parameters. As the number of observed data is greater than the number of parameters, it is always possible to construct a set of kernel equations independent of the setting of discrete parameters. The separation of the continuous part from the discrete parameters model is

Table 1. List of real back azimuths (BA) and apparent back azimuths (BA') in units of degree, derived from each station of MicrOBS.

\begin{tabular}{lrrrrrrr}
\hline & BA & $\pm \sigma_{\mathbf{r}}$ & BA & $\pm \sigma_{\mathbf{a}}$ & Ang_corr. & $\pm \sigma_{\mathbf{s}}$ \\
\hline OBS01 & 154.8 & 0.8 & 0.4 & 8.9 & 154.4 & 9.0 \\
OBS02 & 118.2 & 0.4 & 228.2 & 12.5 & -110.0 & 12.5 \\
OBS03 & 64.5 & 1.2 & 180.5 & 7.8 & -116.0 & 7.9 \\
OBS04 & 99.6 & 1.3 & 127.4 & 7.2 & -27.8 & 7.3 \\
OBS05 & 186.7 & 1.4 & 225.3 & 7.1 & -38.6 & 7.2 \\
OBS06 & 265.4 & 1.7 & 243.8 & 11.1 & 21.6 & 11.2 \\
OBS07 & 1.2 & 3.0 & 359.6 & 5.3 & 1.6 & 6.1 \\
\hline
\end{tabular}

1. Ang corr : value equals to (BA'-BA). Positive means clockwise sense.

2. $\sigma_{r}, \sigma_{a}$ : one standard deviation of the variance of $B A$ and $B A$ ', respectively. The determination is conducted from over 15 events for each station.

3. $\sigma_{s}$ : geometrical mean of $\sigma_{r}, \sigma_{a}$. 
(a)

2005/10/09 21:19:21.0 120.077E 21.321N $12.0 \mathrm{~km}$

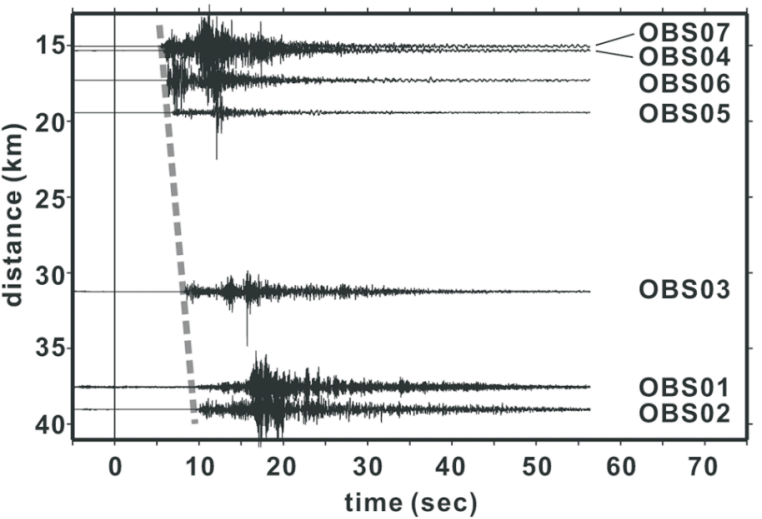

(c)

$2005 / 10 / 09$ 20:15:53.5 120.087E $21.329 \mathrm{~N} 10.4 \mathrm{~km}$ 2005/10/09 20:16:15.0 120.073E 21.332N $15.6 \mathrm{~km}$

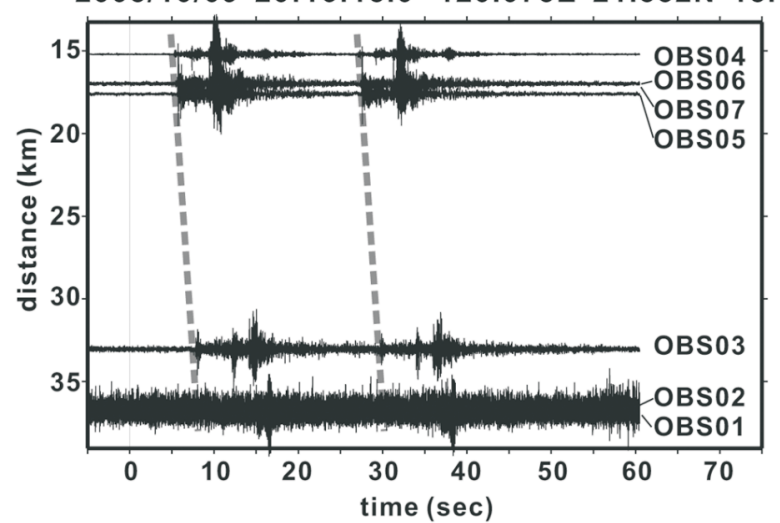

(b)

2005/10/09 21:05:15.6 120.086E 21.309N 5.4 km

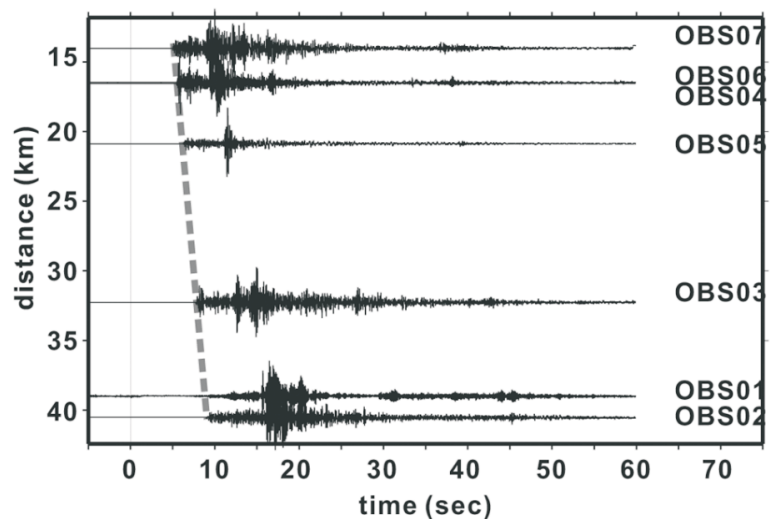

(d)

2005/10/10 21:43:12.4 120.092E $21.296 \mathrm{~N} 10.10 \mathrm{~km}$ 2005/10/10 21:43:25.0 120.090E $21.318 \mathrm{~N} 10.30 \mathrm{~km}$

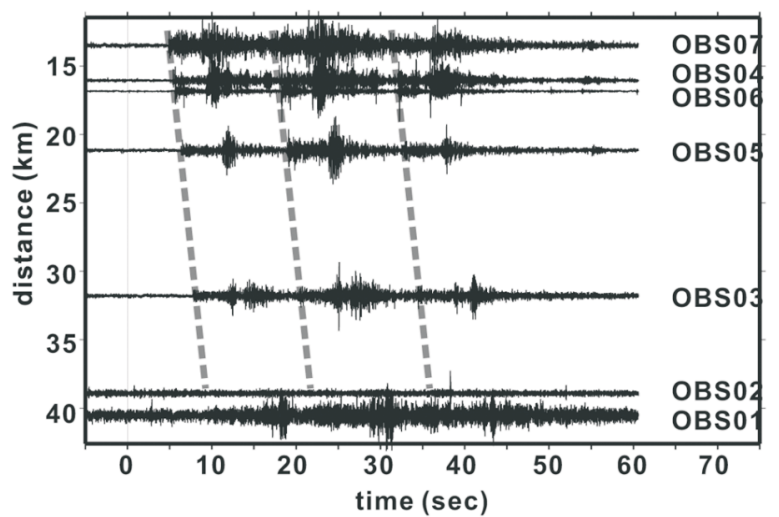

Fig. 4. Examples of earthquake locationing using OBS records, waveforms aligned w.r.t. the epicentral distance (in Y-axis). The dash line indicates the arrival of the direct $P$-phase for each earthquake, showing the increase of the $P$-phase delay time with the epicentral distance. [The third event in (d) is not determined because of a low $\mathrm{S} / \mathrm{N}$ ratio].

natural to the inversion if the hypocenters are estimated initially by conventional least squares using travel times calculated from some initial velocity model. The kernel equations are a set of linear combinations of the residuals unbiased by that initial location, and as a result they can be determined by a Backus-Gilbert procedure (Backus and Gilbert 1970). Our initial $P$-wave velocity model is based on that of CWB (Chen 1995), and the initial $S$-wave velocity model is assumed by setting the $V_{\mathrm{P}} / V_{\mathrm{S}}$ ratio to be 1.74 . Technically, this 1-D model is a product of the averaged seismic effects at each preset layers. The final 1-D velocity model is reached by constraining the travel time residual to be less than 0.1 seconds for $90 \%$ of the events.

Figure 5 illustrates our resultant velocity model, for which the zero level is set as the maximum bathymetry among the 7 OBS stations. Comparing to the other 1-D velocity models constructed by the reflection exploration at SW offshore Taiwan (e.g., Chen and Jaw 1996; McIntosh et al. 2005), our result describes the $P$ - and $S$ - wave velocities down to the greater depth of around $60 \mathrm{~km}$. Our result exhibits a remarkably low velocity in the surface layers, which is consistent with the model of Chen and Jaw (1996, which used 4 OBS receivers) but may be smeared in other seismic reflection experiments. We suspect that such a surface low velocity may be caused by unconsolidated sediments with large water content. For the deeper layers, said around 5 $10 \mathrm{~km}$, our resultant model has a faster $P$-wave velocity than the other models.

Upon closer examination of the velocity perturbation, our model reveals another relatively low velocity zone but a high $V_{\mathrm{P}} / V_{\mathrm{S}}$ ratio $(\sim 1.9)$ at the depth around $2 \sim 4 \mathrm{~km}$. This may be the influence of interbedded fluids or the other local effects. Particularly, it has been largely reported there exists an abundant gas hydrate depositing at SW offshore Taiwan (e.g., Chi et al. 1998; Shyu et al. 1998; Schnurle et al. 1999). Such a low velocity occurred at the shallow layers may be generated by the aggregation of methane gas, as identified by the BSR in the seismic profiles. Further down the seismic 
(a)

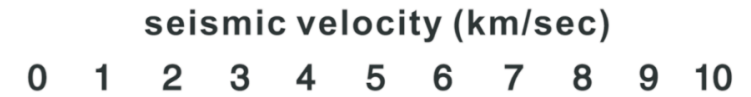

(b)

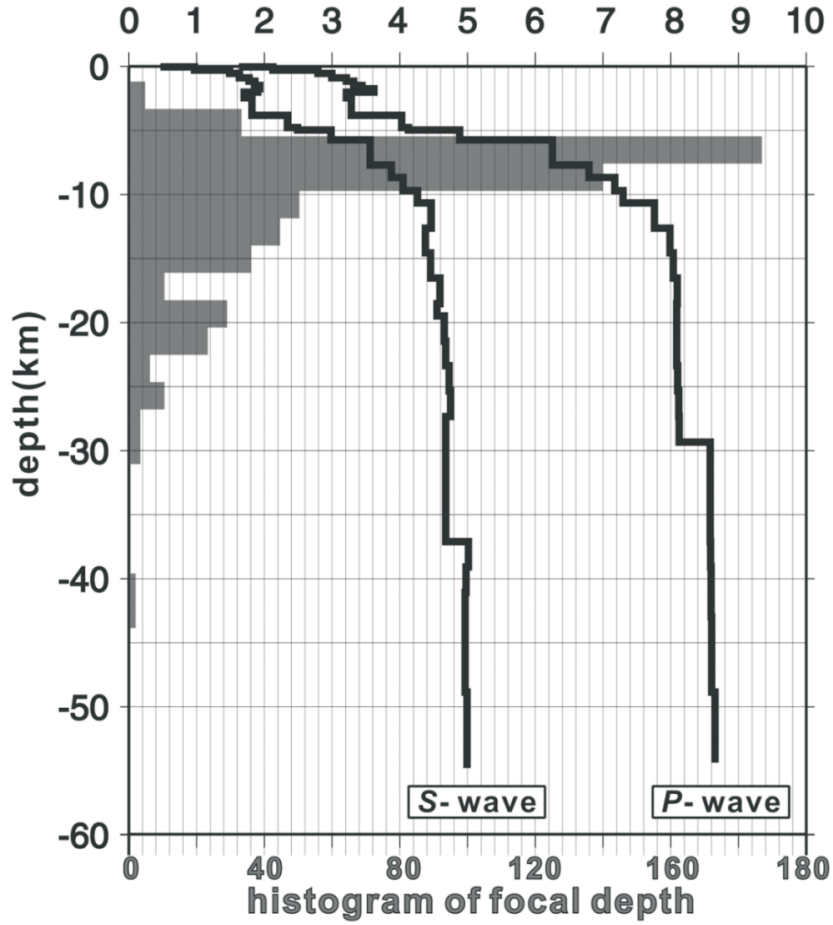

$V_{\mathrm{P}} / V_{\mathrm{S}}$ ratio

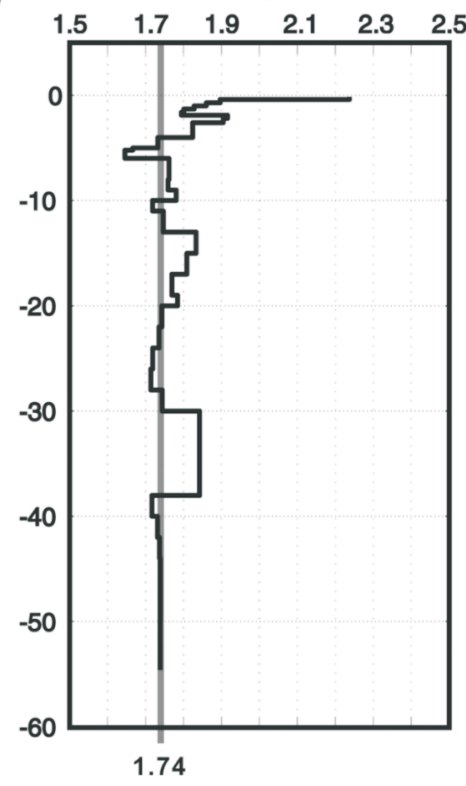

Fig. 5. (a) 1-D layered velocity model derived in this study. The gray bars give the histogram of focal depth, scale at below. (b) The corresponding $V_{\mathrm{P}} / V_{\mathrm{S}}$ ratio.

velocity increases rapidly, reaching $8 \mathrm{~km} \mathrm{sec}^{-1}$ for $P$ wave at the depth around $10 \mathrm{~km}$. Taking into consideration of the critical velocity for compressional wave at the Moho, we identify the Moho boundary to be about $11 \sim 13 \mathrm{~km}$ in depth from the local sea bottom. Beneath Moho is a uniform mantle velocity till the depth around $30 \mathrm{~km}$, where another sharp increasing of velocity is observed. However, this latter is less constrained because few signals come from such depth (see the histogram of earthquake depth in Fig. 5a).

Our resultant 1-D model reveals a clear property of a crust of oceanic origin, with, in particular, the velocity structure of the crustal rock of layer 3 at the depths from 4 to $10 \mathrm{~km}$. The pattern of the derived $V_{\mathrm{P}} / V_{\mathrm{S}}$ ratio along the focal depth generally conforms to the oceanic characteristics (Fig. 5b). A remarkably low $V_{\mathrm{P}} / V_{\mathrm{S}}$ is observed at the depth around $5 \mathrm{~km}$, separating the crust into two divisions corresponding to a high $V_{\mathrm{P}} / V_{\mathrm{S}}(1.8 \sim 2.2)$ and a moderate $V_{\mathrm{P}} / V_{\mathrm{S}}$ $(1.76 \sim 1.79)$. The cause of this low $V_{\mathrm{P}} / V_{\mathrm{S}}$ layer may be related to the change of lithologic composition within the crust, or the transition between the upper and lower crust. Another two notable low $V_{\mathrm{P}} / V_{\mathrm{S}}$ layers are observed at the depths of $10-11 \mathrm{~km}$ and $25-28 \mathrm{~km}$. The former may reflect the variance of mechanical properties near Moho. Otherwise, the $V_{\mathrm{P}} / V_{\mathrm{S}}$ at the depths of $13 \sim 18 \mathrm{~km}$ below Moho has a value about 1.83 , consistent with the general ratio of $V_{\mathrm{P}} / V_{\mathrm{S}}$ for upper mantle (e.g., Nakajima et al. 2001).

With a reliable layered velocity model, we can then re- fine the earthquake parameters. Ultimately after the relocation the travel-time residuals are within 0.3 seconds and generally less than 0.1 seconds. As Fig. 6 shows, the majority of the 406 recorded events concentrate at the shallow layers, largely around $5 \sim 7 \mathrm{~km}$, and almost all the events occurred at a limited location forming a vertical chain at the spot of $20.5^{\circ}$ latitude and $120.5^{\circ}$ longitude, from 5 to $40 \mathrm{~km}$ in depth penetrating the whole lithosphere. Along the depth profiles in the EW and NS direction, it shows a northeast trend at the depth of $30 \mathrm{~km}$ (Figs. 6a, b). It is worth noting here that exists a seismic gap at the depth around $10 \sim 13 \mathrm{~km}$, which is that of the Moho revealed from the layered velocity model and may be related to the rheologic variance. The mainshock of this earthquake sequence is located within this earthquake swarm, with magnitude 4.5 and origin time at 21:05:15 9 October 2005. The bold gray line in Fig. 7 indicates the cumulative event number (scaled by the left Y-axis) along the time axis. The relationship of the focal depth of events (scaled by the right Y-axis) versus their origin times is also provided in Fig. 7 with black crosses. Timing of the mainshock occurrence is marked by a bold dash line. There is an apparent increase of earthquake number right after the mainshock. Prior to that, seismic activity is mainly bounded at the shallow layers within $10 \mathrm{~km}$, but spreads in a wider range from 5 to $30 \mathrm{~km}$ afterwards in vertical direction.

Previous studies on the subduction seismicity also reported the existence of the vertical delineation of aftershocks 
(a)

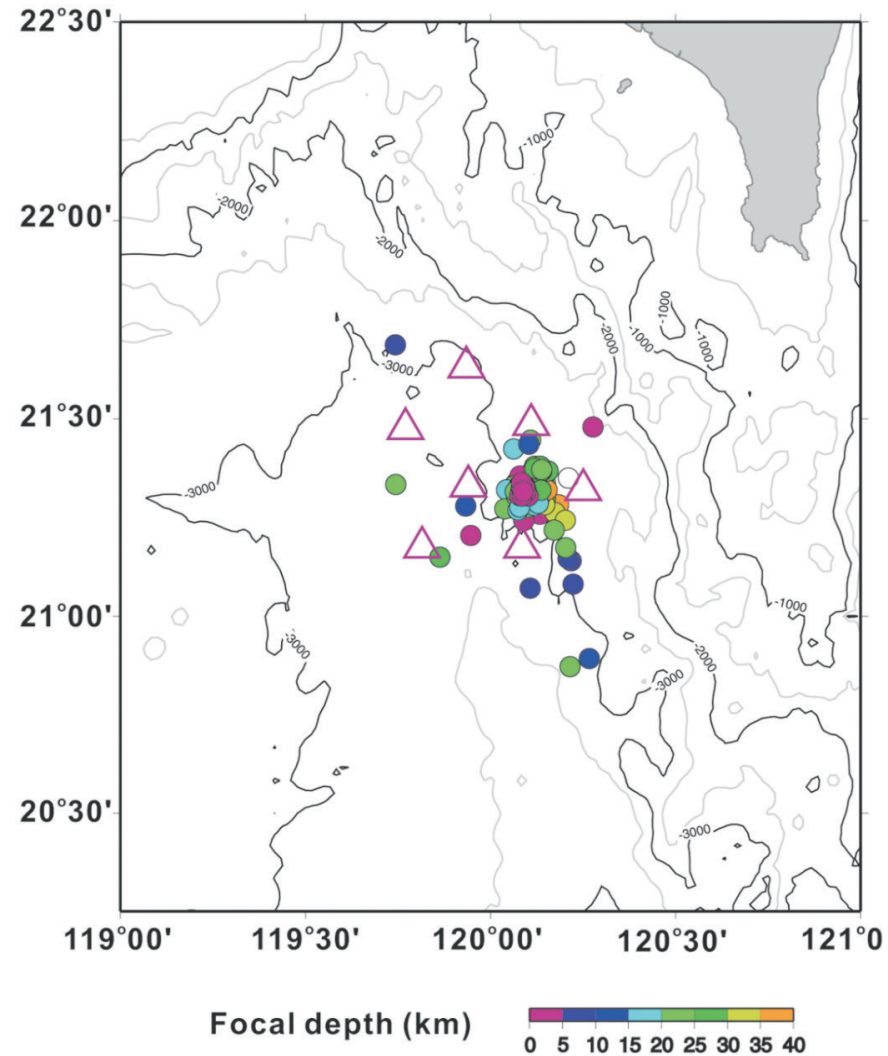

(b)

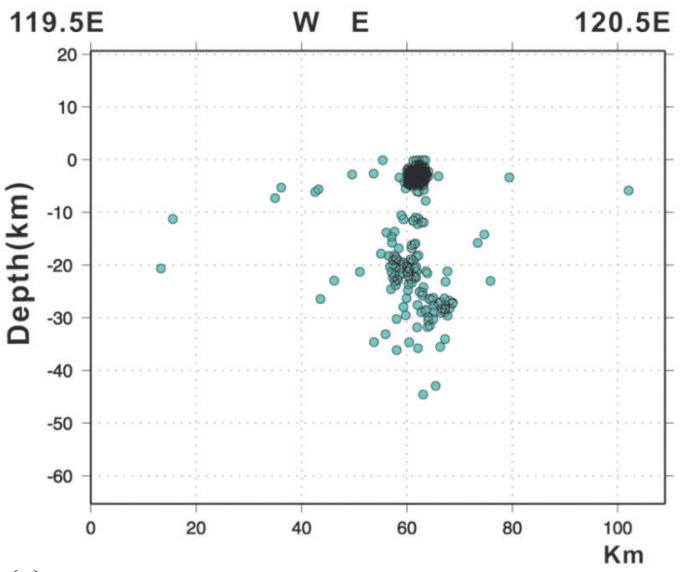

(c)

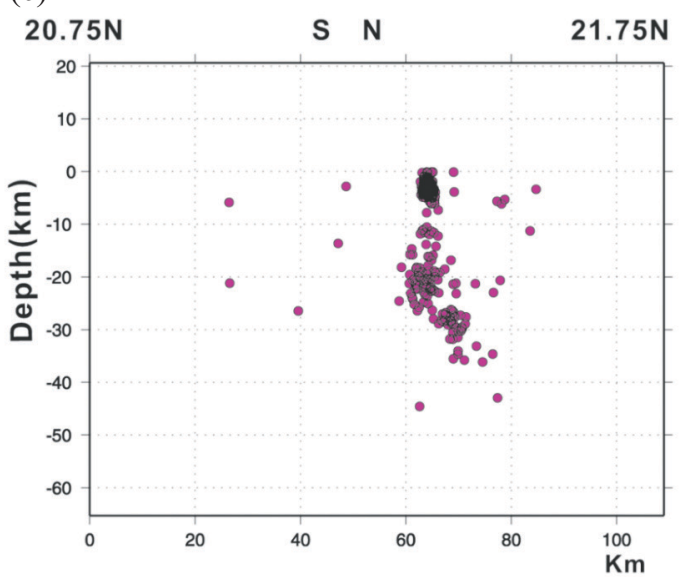

Fig. 6. (a) Map view of the earthquakes detected by the OBS array. (b) and (c) are the vertical profiles in the EW and NS directions, respectively.

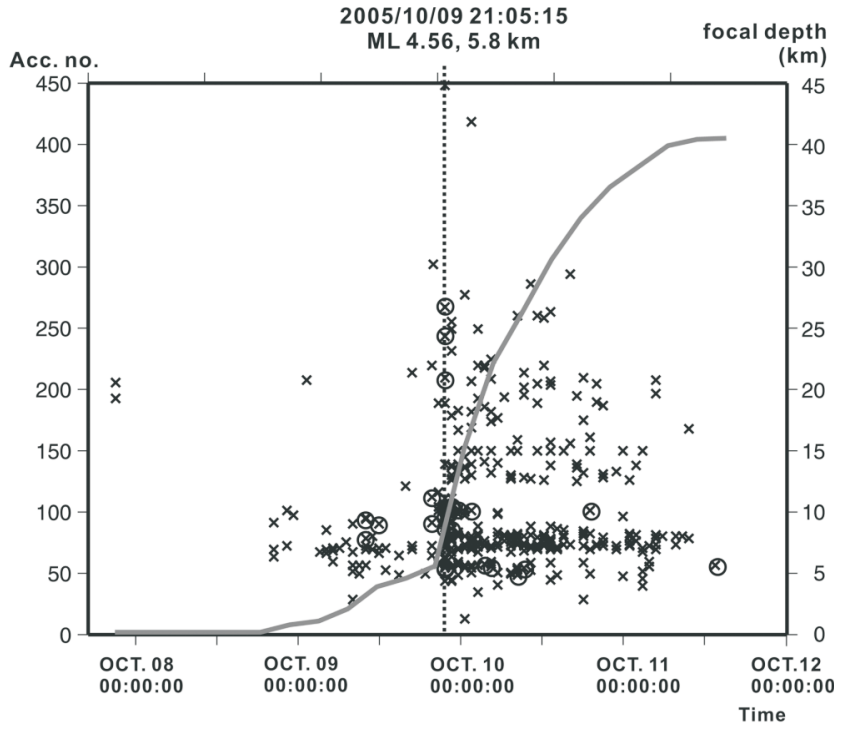

Fig. 7. The earthquake sequence w.r.t. the calendar days. The gray curve gives the cumulative earthquake index number with time (scale on the left); the cross shows the relation of the focal depth with the corresponding origin time (scale on the right). The dash line marks the occurrence of the main event (magnitude 4.5, 9 Oct. 2005). Black circles mark the 26 events we have solved for focal mechanism in Fig. 8 and Table 2. that is located at the top of the Wadati-Benioff zone or passes through the hypocenter of the main event (e.g., Hansen and Ratchkovsi 2001; Choy and Kirby 2004). They inferred that intraslab earthquakes could have ruptured into the upper mantle of the subducting lithosphere or, alternatively, that it could stress the upper mantle sufficiently to induce secondary activities. In this study, however, no sufficient observations can distinctly link for the OBS detection with the consequent events. In terms of spatial distribution, our OBS array is not far from the 2006 Pingtung earthquake sequence. They might exhibit a tectonic coherence between the two earthquakes as being affected by a similar regional tectonic stress. Future study combining the OBS data with the CWB on-land records may resolve better the seismotectonics structure in the southern extreme of Taiwan.

\section{FOCAL MECHANISM SOLUTIONS}

Given a reasonably good station coverage for an earthquake in a region for which the velocity structure is well defined, together with well recorded impulsive $P$-wave first arrivals, one can get a reliable estimate for the fault-plane solu- 
tion of the event. In this study, locations of the detected earthquakes lie within our OBS array with a good azimuthal coverage. As our station density is low, sometimes we have to introduce the amplitude ratio of $S V$ to $P$ in order to better constrain the attitude of the nodal planes in the stereographic statistics (Kisslinger et al. 1981, 1982; Snoke et al. 1984; Snoke 2003). The main program, Focmec, conducts an efficient, systematic search of the focal sphere and reports acceptable solutions even with few stations (Snoke et al. 1984; Snoke 2003). Ultimately, we obtain robust focal mechanism solutions for 26 earthquakes in our OBS recordings, as marked by circles in Fig. 7. Most of these solutions are from the shallow events taking place after the mainshock of October 9. Table 2 lists these solutions with index of their origin times, and Fig. 8 illustrates them in the lower hemispheric projection.

The mainshock mentioned above is numbered as 7 within these earthquakes, which shows a strike-slip dominant rupture. Except for two solutions with a normal-faulting mechanism (Nos. 3, 12), the deformation mechanism of these events is principally in oblique convergence combined with reverse and strike-slip motions. Only three events (Nos. 8, 10, and 14) happened deeper than $20 \mathrm{~km}$. They have a typical strike-slip motion (Table 2, Fig. 8), demonstrating a

Table 2. The 26 focal mechanism solutions derived from the OBS observations.

\begin{tabular}{|c|c|c|c|c|c|c|c|c|c|c|c|c|}
\hline Event & $\begin{array}{c}\text { Date } \\
\text { year/month/day }\end{array}$ & $\begin{array}{c}\text { Origin Time } \\
\text { UT }\end{array}$ & $\mathbf{M}_{\mathbf{L}}$ & $\begin{array}{c}\text { Long. } \\
{ }^{\circ} \mathbf{E}\end{array}$ & $\begin{array}{l}\text { Lat. } \\
{ }^{\circ} \mathbf{N}\end{array}$ & $\begin{array}{c}\text { Depth } \\
\text { km }\end{array}$ & $\begin{array}{c}\text { strike1 } \\
\text { deg. }\end{array}$ & $\begin{array}{l}\text { dip1 } \\
\text { deg. }\end{array}$ & $\begin{array}{c}\text { rake1 } \\
\text { deg. }\end{array}$ & $\begin{array}{c}\text { strike2 } \\
\text { deg. }\end{array}$ & $\begin{array}{l}\text { dip2 } \\
\text { deg. }\end{array}$ & $\begin{array}{c}\text { rake2 } \\
\text { deg. }\end{array}$ \\
\hline 1 & $2005 / 10 / 09$ & $09: 34: 31.5$ & 3.09 & 120.092 & 21.298 & 9.4 & 251 & 15 & 119 & 41 & 77 & 82 \\
\hline 2 & $2005 / 10 / 09$ & $09: 34: 31.3$ & 3.04 & 120.081 & 21.300 & 7.8 & 313 & 20 & 157 & 65 & 82 & 71 \\
\hline 3 & $2005 / 10 / 09$ & 11:12:50.9 & 1.92 & 120.089 & 21.306 & 9.0 & 198 & 41 & -81 & 6 & 50 & -98 \\
\hline 4 & $2005 / 10 / 09$ & $19: 23: 55.9$ & 2.97 & 120.087 & 21.297 & 11.2 & 244 & 64 & -178 & 154 & 89 & -26 \\
\hline 5 & $2005 / 10 / 09$ & $19: 23: 55.1$ & 2.92 & 120.092 & 21.307 & 9.1 & 238 & 20 & 100 & 37 & 70 & 86 \\
\hline 6 & $2005 / 10 / 09$ & 21:02:12.1 & 4.17 & 120.095 & 21.299 & 8.7 & 4 & 66 & -156 & 264 & 68 & -26 \\
\hline 7 & $2005 / 10 / 09$ & 210:5:15.6 & 4.46 & 120.086 & 21.309 & 5.4 & 68 & 52 & 4 & 336 & 87 & 132 \\
\hline 8 & $2005 / 10 / 09$ & 21:06:51.3 & 2.8 & 120.188 & 20.926 & 21.0 & 358 & 62 & -165 & 261 & 77 & -29 \\
\hline 9 & $2005 / 10 / 09$ & $21: 08: 25.4$ & 2.69 & 120.091 & 21.304 & 6.0 & 65 & 45 & 130 & 195 & 57 & 57 \\
\hline 10 & $2005 / 10 / 09$ & 21:09:11.2 & 3.39 & 120.164 & 21.276 & 27.0 & 151 & 78 & -168 & 61 & 88 & -2 \\
\hline 11 & $2005 / 10 / 09$ & & 1.93 & 120.083 & 21.295 & 9.0 & 268 & 20 & 157 & 20 & 82 & 71 \\
\hline 12 & $2005 / 10 / 09$ & & 2.88 & 120.078 & 21.319 & 10.0 & 241 & 39 & -111 & 49 & 54 & -74 \\
\hline 13 & $2005 / 10 / 09$ & & 2.86 & 120.074 & 21.316 & 10.0 & 227 & 38 & 126 & 4 & 60 & 65 \\
\hline 14 & $2005 / 10 / 09$ & $21: 39: 28.1$ & 2.62 & 120.086 & 21.277 & 24.0 & 137 & 82 & 173 & 228 & 83 & 9 \\
\hline 15 & $2005 / 10 / 09$ & $22: 02: 47.6$ & 2.86 & 120.094 & 21.308 & 10.0 & 57 & 50 & 158 & 161 & 73 & 42 \\
\hline 16 & $2005 / 10 / 09$ & 22:13:06 & 2.46 & 120.088 & 21.319 & 8.0 & 78 & 52 & 146 & 191 & 64 & 43 \\
\hline 17 & 2005/10/09 & $22: 18: 24.3$ & 2.89 & 120.097 & 21.313 & 10.0 & 238 & 75 & -165 & 148 & 85 & -21 \\
\hline 18 & $2005 / 10 / 09$ & $22: 59: 49.8$ & 2.49 & 120.079 & 21.311 & 10.0 & 241 & 25 & 132 & 15 & 71 & 72 \\
\hline 19 & $2005 / 10 / 09$ & $23: 04: 27.5$ & 4.04 & 120.093 & 21.309 & 10.0 & 57 & 48 & 151 & 168 & 69 & 46 \\
\hline 20 & $2005 / 10 / 10$ & 01:29:39.5 & 3.78 & 120.078 & 21.319 & 10.0 & 246 & 81 & -173 & 155 & 83 & -9 \\
\hline 21 & $2005 / 10 / 10$ & 03:15:00.9 & 2.13 & 120.096 & 21.308 & 6.0 & 43 & 45 & 49 & 274 & 58 & 124 \\
\hline 22 & $2005 / 10 / 10$ & 04:15:06.5 & 3.35 & 120.079 & 21.306 & 6.0 & 297 & 34 & 135 & 66 & 67 & 64 \\
\hline 23 & $2005 / 10 / 10$ & 08:14:03.9 & 2.49 & 120.088 & 21.311 & 5.0 & 38 & 24 & -161 & 290 & 82 & -67 \\
\hline 24 & $2005 / 10 / 10$ & 09:22:28.4 & 2.33 & 120.086 & 21.314 & 5.0 & 263 & 79 & -10 & 355 & 80 & -169 \\
\hline 25 & $2005 / 10 / 10$ & $19: 16: 22.9$ & 2.9 & 120.092 & 21.313 & 10.0 & 179 & 30 & -4 & 273 & 88 & -120 \\
\hline 26 & $2005 / 10 / 11$ & $14: 34: 32.0$ & 4.9 & 120.085 & 21.310 & 6.0 & 248 & 38 & 126 & 25 & 60 & 65 \\
\hline
\end{tabular}




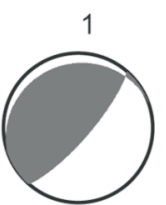

$(3.1,9.4)$

9

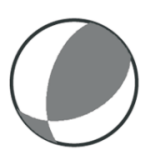

$(2.7,5.5)$

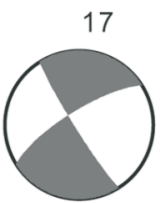

$(2.9,10.5)$

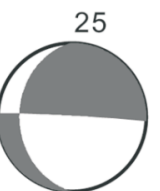

$(2.9,10.1)$

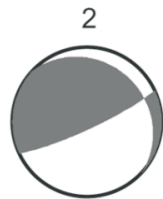

$(3.0,7.8)$

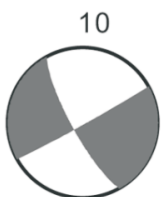

$(3.4,26.8)$

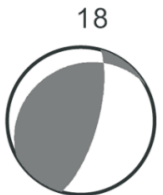

$(2.5,10.5)$

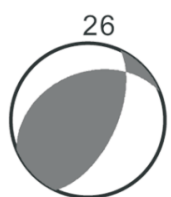

$(4.9,5.6)$

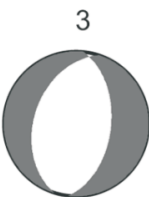

$(1.9,9.0)$

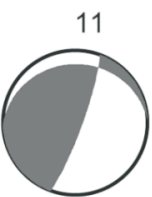

$(1.9,9.6)$

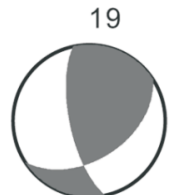

$(4.0,10.1)$

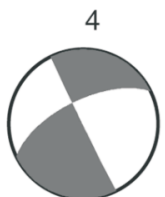

$(2.9,11.2)$

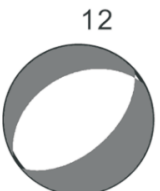

$(2.9,10.3)$

20

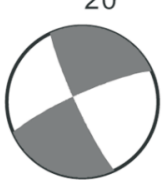

$(3.8,10.2)$

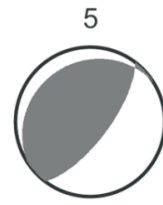

$(2.9,9.1)$

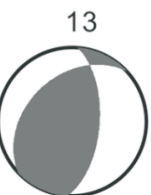

$(2.9,9.6)$

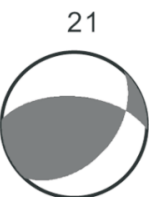

$(2.1,5.7)$

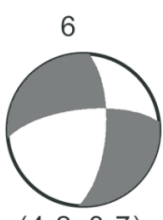

$(4.2,8.7)$

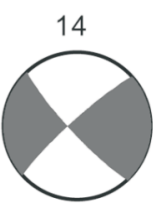

$(2.6,24.4)$

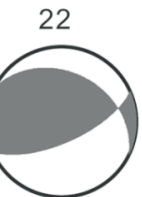

$(3.4,5.5)$
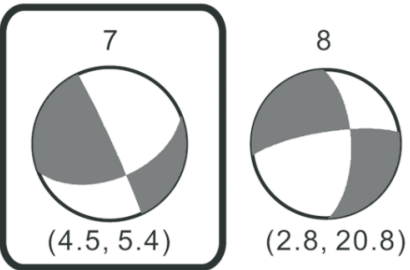

15

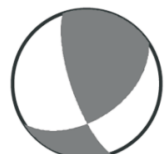

(2.9, 10.3

23

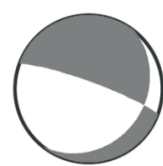

$(2.5,4.8)$

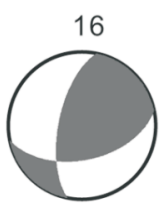

$(2.5,8.6)$

24

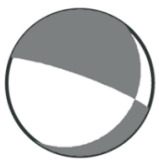

$(2.3,5.4)$

Fig. 8. The 26 focal mechanism solutions (lower hemispheric projection). The number on top is the order in the occurrence sequence; numbers in parenthesis at bottom indicate (magnitude, focal depth in $\mathrm{km}$ ). Compression quadrant is in black. The rectangle marks the mainshock in the sequence.

transient lateral faulting in the upper mantle for the local lithosphere. In contrast, the shallow earthquakes are dominated by reverse mechanisms, possibly caused by a convex slip along the up warp faulting plane extending from the deeper strike-slip rupture to the superficial reverse motion. If so, all the detected events may lie on a fault-plane in the NE-SW direction. However, the very limited spatial distribution of seismicity detected by the OBS array cannot provide more detailed information for the attitude of the rupture plane.

Another pattern worth noting is the inconsistency of the focal mechanism along the time sequence. It shows that the ruptures could be in a reverse sense among these events (Fig. 8). This phenomenon is rare, but reported in other areas with shallow earthquakes, e.g., the shallow seismotectonics in the south Iceland (Einarsson et al. 1981; Angelier et al. 2004, 2007), the micro-earthquakes in the eastern Egypt (Daggett et al. 1986; Badawy et al. 2008), and so on. It suggests that the local effects, such as the elastic rebound, stress drop, material intrusion and maybe fluid migration, would cause temporal variances of the local stress/strain regime and therefore generate a large dispersion in the local focal mechanisms. This makes the mechanisms of rupture as functions of time and space (Angelier et al. 2007; Badawy et al. 2008).

Thus, in our OBS observation we consider that the vari- ance of the focal mechanism solutions conforms to the local settings of strain field, which characterizes a locally backand-forth rupture motion in a short term. The pre-existing structures at SW offshore Taiwan area may play an important role in this scenario.

\section{DISCUSSIONS}

Our OBS array observations and results above can be compared with simultaneous recording by the CWB onland network. Its station azimuthal coverage restricted only in the $\mathrm{NE}$ and being more distant, the CWB catalog contains only 27 events, a small subset of the 406 events. Figure 9 presents 11 such recorded events with magnitudes ranging from 2.8 to 4.9. The CWB's catalog shows a much more scattered pattern for the hypocentral locations relative to our OBS determination. It also tends to put the hypocenters at deeper depth and closer to the Taiwan island.

We further collect the $P$-, $S$ - travel times (according to our OBS determination) of the 27 earthquakes recorded among some 65 land stations, and plot them with respect to their epicentral distance in Fig. 10. The $P$-, $S$ - arrival times for the near field at distance within $\sim 45 \mathrm{~km}$ are our OBS detections; those at the intermediate-to-far fields beyond $45 \mathrm{~km}$ are according to CWB. It is shown that the origin times derived by the OBS observations conform to the $P$-, $S$ - 
(a)

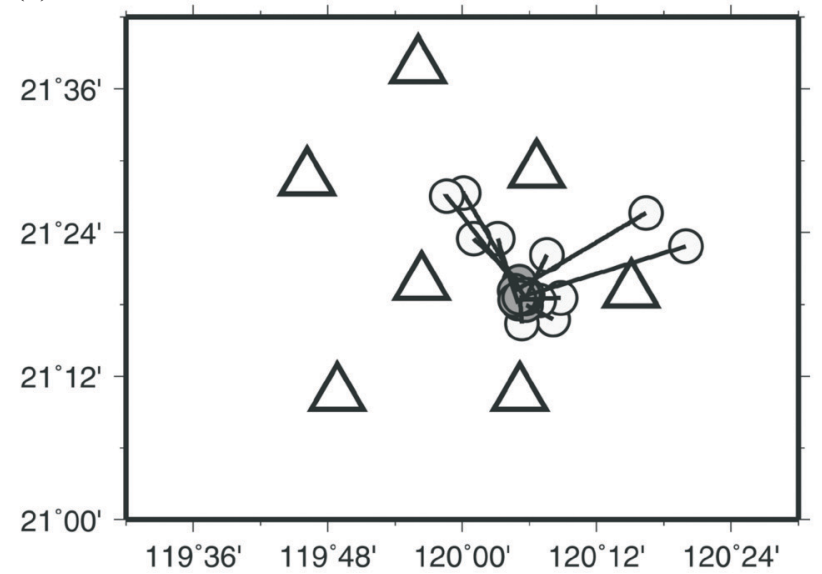

(b)

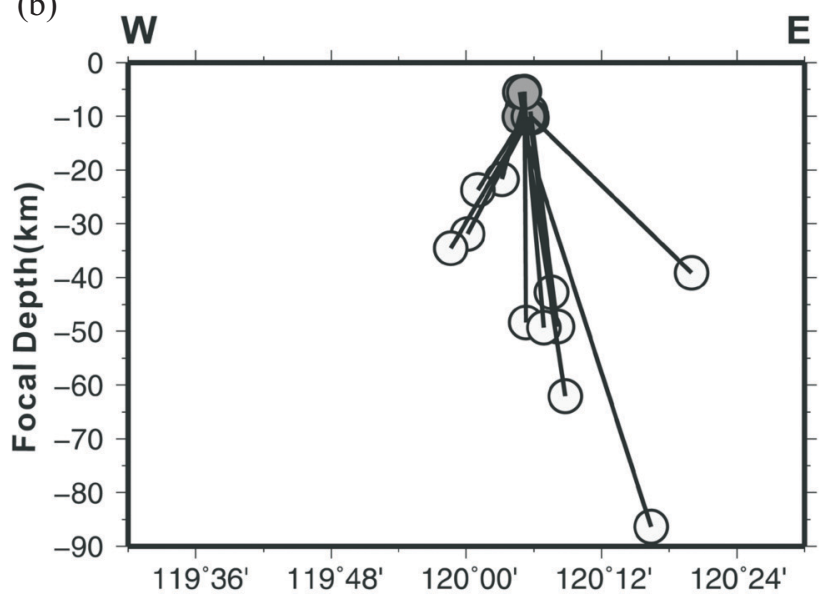

Fig. 9. (a) Map view of the earthquake locations according to the CWB catalog (open circle) and determined by our OBS array (close circle). Triangles are the OBS stations. (b) The same comparison in vertical profile.

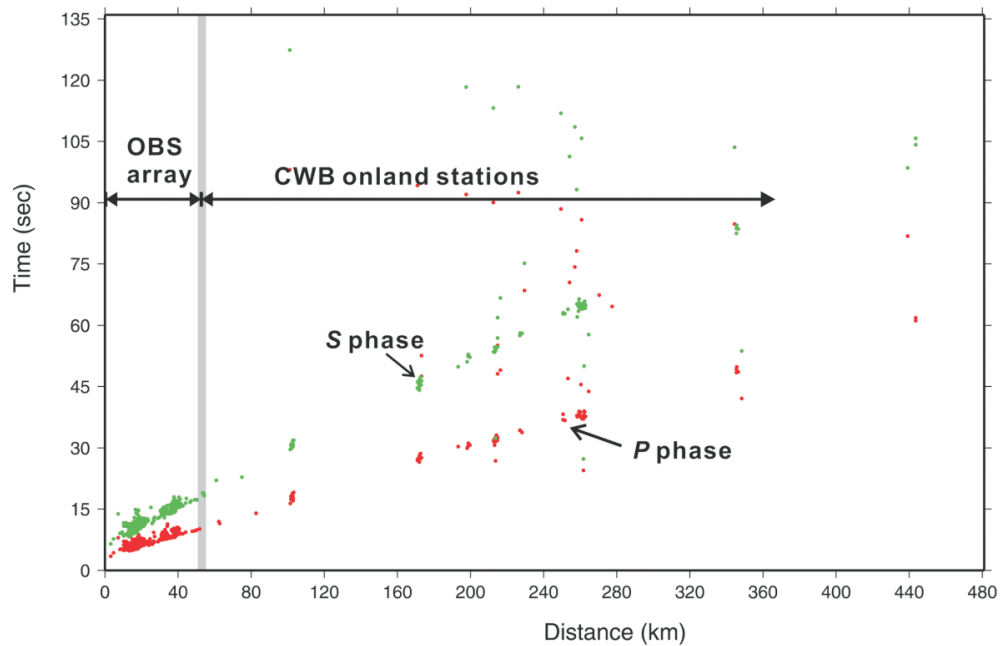

Fig. 10. $P$-, $S$-phase travel times versus the earthquakes' epicentral distance to the stations. by the OBS observation may not be the basic background pattern of seismicity in this area.

The seismogenic character in the SW offshore Taiwan revealed by the OBS observation seems to have little relationship with the typical subduction system, even though the surface trace of the Manila trench can extend to this area. The trench morphology identified at the SW offshore Taiwan probably corresponds to the western front of the accretionary prism in southern Taiwan. The erosion of the deep marine canyons could sculpture the sea-bottom relief and link the morphologic connection of the accretionary prism with the tectonic trench. In contrast, the tectonic trenching by the plate subduction may have ended at the south of our studies area. How to clarify the transition from the active subduction to the trench ending awaits further study.

travel times as a well-formed function of the epicentral distance, whether with the OBS or the CWB stations, implying that our earthquake locations are more reliable. Joining the marine and land observations can presumably reveal further structures from the sea to the continent.

Examining the focal depth relative to the origin time, a general scenario of earthquake sequence emerges - firstly happening at shallow layers less than $10 \mathrm{~km}$, and then extending to the depth until $40 \mathrm{~km}$, which is consistent with the occurrence of the bigger, magnitude 4.5 earthquake on Oct 9. We tend to consider the background seismicity being basically at the shallow layers and rarely deeper except the larger earthquakes. There are only about 60 earthquakes in the CWB catalog from 1990 to 2005 with magnitude exceeding 4.0 for this area. Such a small number of larger earthquakes leads us to consider the vertical seismicity pattern revealed
Acknowledgements The authors would like to thank the Institute of Applied Geosciences of the National Taiwan Ocean University (NTOU), for providing the MicrOBS instruments. The assistance of Mr. Ching-Wei Liang, who is the MicrOBS specific technician in NTOU, did great efforts in operating MicrOBS during the research cruises. We have benefited from discussions with Drs. Jacques Angelier, Ling-Yun Chiao, Ho-Shin Yu, Han-Chien Chou, and Andrew Lin. We are indebted to the two anonymous reviewers who provided much helpful criticism. This study is funding by the National Science Council grant NSC96-2116-M002-012.

\section{REFERENCES}

Angelier, J., R. F. Slunga, F. Bergerat, R. Stefansson, and C. 
Homberg, 2004: Perturbation of stress and oceanic rift extension across transform faults shown by earthquake focal mechanisms in Iceland. Earth Planet. Sci. Lett., 219, 271284.

Angelier, J., F. Bergerat, R. Stefansson, and M. Bellou, 2007: Seismotectonics of a newly formed transform zone near a hotspot: Earthquake mechanisms and regional stress in the South Iceland Seismic Zone. Tectonophysics, doi: 10.1016/ j.tecto.2006.07.016.

Auffret, Y., P. Pelleau, F. Klingelhoefer, J. Crozon, J. Y. Lin, and J. C. Sibuet, 2004: MicrOBS: A new ocean bottom seismometer generation. First Break, 22, 41-47.

Backus, G. E. and F. Gilbert, 1970: Uniqueness in the inversion of inaccurate gross earth data. Phil. Trans. Roy. Soc. London, Ser. A, 266, 123-192.

Badawy, A., S. El-Hady, and A. K. Abdel-Fattah, 2008: Microearthquakes and neotectonics of Abu-Babbab, eastern desert of Egypt. Seismol. Res. Lett., 79, 55-67.

Briais, A., P. Patriat, and P. Tapponnier, 1993: Updated interpretation of magnetic anomalies and seafloor spreading stages in South China Sea: Implications for the Tertiary tectonics of Southeast Asia. J. Geophys. Res., 98, 62996328 .

Chen, A. and Y. S. Jaw, 1996: Velocity structure near the northern Manila trench: An OBS refraction study. Terr. Atmos. Ocean. Sci., 7, 277-297.

Chen, Y. L., 1995: A study of 3-D velocity structure of the crust and the subduction zone in the Taiwan region. Master Thesis, Natl. Cent. Univ., Chung-Li, Taiwan, ROC, 172 pp. (in Chinese)

Chi, W. C., D. L. Reed, C. S. Liu, and E. Lausch, 1998: Distribution of the bottom-simulating reflector in the offshore Taiwan collision zone. Terr. Atmos. Ocean. Sci., 9, 779794.

Choy, G. L. and S. H. Kirby, 2004: Apparent stress, fault maturity and seismic hazard for normal-fault earthquakes at subduction zones. Geophys. J. Int., 159, 991-1012.

Daggett, P. H., P. Morgan, F. K. Boulos, S. Hennin, A. ElSherif, A. Al-Sayed, N. Basta, and Y. S. Melek, 1986: Seismicity and active tectonics of the Egyptian Red Sea margin and northern Red Sea. Tectonophysics, 125, 313-324.

Einarsson, P., S. Björnsson, G. Foulger, R. Stefansson, and T. Skaftadottir, 1981: Seismicity pattern in the South Iceland Seismic Zone. In: Simpson, D. W., P. G. Richards (Eds.), Earthquake Prediction: An International Review, Maurice Ewing Series 4, Washington DC, 141-151.

Gutenberg, B. and C. F. Richter, 1956: Earthquake magnitude, intensity, energy and acceleration. Bull. Seismol. Soc. Am., 46, 105-145.

Hansen, R. A. and N. A. Ratchkovski, 2001: The Kodiak Island, Alaska $\mathrm{M}_{\mathrm{w}} 7$ earthquake of 6 December 1999. Seismol. Res. Lett., 72, 22-32.

Hsu, S. K. and J. C. Sibuet, 2004: Continent-Ocean transition of the northern South China Sea and off southwestern Taiwan. Mar. Geophys. Res., 25, 1-4.
Hsu, S. K., Y. C. Yeh, W. B. Doo, and C. H. Tsai, 2004: New bathymetry and magnetic lineations identifications in the northernmost South China Sea and their tectonic implications. Mar. Geophys. Res., 25, 29-44.

Kissling, E., W. L. Ellsworth, D. Eberhart-Phillips, and U. Kadolfer, 1994: Initial reference models in local earthquake tomography. J. Geophys. Res., 99, 19635-19646.

Kisslinger, C., J. R. Bowman, and K. Koch, 1981: Procedures for computing focal mechanism from local (SV/P) ratios. Bull. Seismol. Soc. Am., 71, 1718-1729.

Kisslinger, C., J. R. Bowman, and K. Koch, 1982: Determination of focal mechanisms from (SV/P) amplitude ratios at small distances. Phys. Earth Planet. Inter., 30, 172-176.

Liu, C. S., I. L. Huang, and L. S. Teng, 1997: Structure features off southwestern Taiwan. Mar. Geol., 137, 305-319.

McIntosh, K., Y. Nakamura, T. K. Wang, R. C. Shih, A. Chen, and C. S. Liu, 2005: Crustal-scale seismic profiles across Taiwan and the western Philippine Sea. Tectonophysics, 401, 23-54.

Nakajima, J., T. Matsuzawa, A. Hasegawa, and D. Zhao, 2001: Seismic velocity structure and $\mathrm{Vp} / \mathrm{Vs}$ structure beneath the northeastern Japan Arc as inferred from seismic travel time tomography. Bull. Earthq. Res. Inst., 76, 13-21.

Nakamura, Y., K. McIntosh, and A. Chen, 1998: Preliminary results of a large offset seismic survey west of Hengchun peninsula, southern Taiwan. Terr. Atmos. Ocean. Sci., 9, 395-408.

Pavlis, G. L. and J. R. Booker, 1980: The mixed Discrete-continuous inverse problem: Application to the simultaneous determination of earthquake hypocenters and velocity structure. J. Geophys. Res., 85, 4801-4810.

Pulliam, J., Y. Nakamura, C. Huerta-Lopez, and B. Yates, 2003: Field test of an inexpensive, small broadband Ocean-Bottom seismograph. Bull. Seismol. Soc. Am., 93, 1, 152-171.

Rangin, C., W. Spakman, M. Pubellier, and H. Bijwaard, 1999: Tomographic and geological constraints on subduction along the eastern Sundal and continental margin (SouthEast Asia). Bulletin de la Société Géologique de France, 170, 755-788.

Rau, R. J. and F. T. Wu, 1995: Tomographic imaging of lithospheric structures under Taiwan. Earth Planet. Sci. Lett., 133, 517-532.

Schnurle, P., T. H. Hsiuan, and C. S. Liu, 1999: Constraints on free gas and gas hydrate bearing sediments from multichannel seismic data, offshore southwestern Taiwan. Petrol. Geol. Taiwan, 33, 21-42.

Shyu, C. T., S. K. Hsu, and C. S. Liu, 1998: Heat flows off southwest Taiwan: measurements over mud diapirs and estimated from bottom-simulating reflectors. Terr. Atmos. Ocean. Sci., 9, 795-821.

Sibuet, J. C., S. K. Hsu, and A. Normand, 2004: Tectonic significance of the Taitung Canyon, Huatung Basin, east of Taiwan. Mar. Geophys. Res., 25, 95-107.

Snoke, J. A., 2003: FOCMEC: FOcal MEChanism determina- 
tions, International Handbook of Earthquake and Engineering Seismology. In: Lee, W. H. K., H. Kanamori, P. C. Jennings, and C. Kisslinger (Eds.), Academic Press, San Diego, Chapter 85.12.

Snoke, J. A., J. W. Munsey, A. C. Teague, and G. A. Bollinger, 1984: A program for focal mechanism determination by combined use of polarity and SV-P amplitude ratio data. Earthq. Notes, 55, 15.

Tapponnier, P., G. Peltzer, A. Y. L. Dain, and R. Armijo, 1982: Propagating extrusion tectonics in Asia: New insights from simple experiments with plasticine. Geology., 10, 611-616.

Taylor, B. and D. E. Hayes, 1980: The Tectonic evolution of the South China basin. In: Hayes, D. E. (Ed.), The Tectonic and Geologic Evolution of Southern Asian Seas and Is- lands, 1. Am. Geophys. Union, Washington, DC, 89-104.

Tsai, Y. B., 1986: Seismotectonics of Taiwan. Tectonophysics, 125, 17-37.

Wang, C. Y. and T. C. Shin, 1998: Illustrating 100 years of Taiwan seismicity. Terr. Atmos. Ocean. Sci., 9, 589-614.

Webb, S. C., 1998: Broadband seismology and noise under the ocean. Rev. Geophys., 36, 105-142.

Wu, H. H., Y. B. Tsai, T. Y. Lee, C. H. Lo, C. H. Hsieh, and D. V. Toan, 2004: 3-D shear wave velocity structure of the crust and upper mantle in South China Sea and its surrounding regions by surface wave dispersion analysis. Mar. Geophys. Res., 25, 5-27.

Yu, S. B., H. Y. Chen, and L. C. Kuo, 1997: Velocity field of GPS stations in the Taiwan area. Tectonophysics, 274, 41-59. 